\title{
Bitumen Recovery from Oil Sands Mature Fine Tailings
}

\author{
G. R. D. Elliott*, V. A. Munoz* and R. J. Mikula*
}

*CanmetENERGY, Devon Research Centre, Natural Resources Canada, 1 Oil Patch Drive, Devon, Alberta, Canada, T9G 1A8

The extraction of the bitumen from the oil sand in surface mined operations creates a large amount of mine tailings. This is leftover material, typically sand, silt, and clays, with some residual bitumen. The efficiency of the bitumen removal from the oil sand is affected by a variety of factors including the process temperature, the process water chemistry, the amount of clay present, and by the bitumen chemistry. The bitumen lost to tailings during the extraction process tends to have a higher degree of oxidation or surfactant loading that hinders initial floatation. The bitumen that has collected over the years in the tailings ponds started out with a higher propensity to associate with the clay minerals, and after years of exposure to bacterial activity and other chemical changes, recovery of bitumen from the tailings is even more of a challenge. Many of the surface mined oil sands operations are at a stage where treatment of the tailings and reclamation of the original boreal forest and wetland areas is beginning. This involves transferring and treating millions of cubic meters of fluid fine tailings (often called mature fine tailings or MFT). The residual bitumen is associated with the MFT, and not with the sand tailings that are used to contain the large volumes of MFT. Mature fine tailings with a typical 1-3\% bitumen content represents a significant source of bitumen in the ponds. If this bitumen could be economically extracted, this revenue stream could help pay for the reclamation costs. In addition, if the residual bitumen content can be reduced to allow enough level, this tailings material could be used directly in the reclamation process, negating the current plan to cap with sand, overburden, and finally to reclaim on the original soil horizon.

This study was aimed at developing a method of extracting bitumen from mature fine tailings in order to: 1) decrease the amount of bitumen in reclaimed mature fine tails for landscape reclamation; and 2) chemically treat the resulting bitumen so it can be introduced into an existing froth plant streams for treatment without deleterious emulsification effects due to the high surfactant loading. We have developed a two step process that first involves a dilution, mixing and aeration of the mature fine tails to produce a primary recovery product, which has a high amount of oxidized bitumen and solids. The second step involved the treatment of the primary recovery product with $3000 \mathrm{ppm} \mathrm{NaOH}$ to produce high quality bitumen froth (high bitumen to solids ratio). By treating with a high concentration of $\mathrm{NaOH}$, it will reduce the amount of oxidized bitumen, move the surfactants from the bitumen to the water phase, and therefore allow for a significant reduction of solids content of the froth (FIG. 1). Microscopic methods for the evaluation of surfactant partitioning in the bitumen were essential for the development of this bitumen recovery process (FIG. 2). Results indicate that this two step process could create a bitumen product from mature fine tailings that could blend with the primary extraction bitumen and not cause any downstream emulsification problems. 

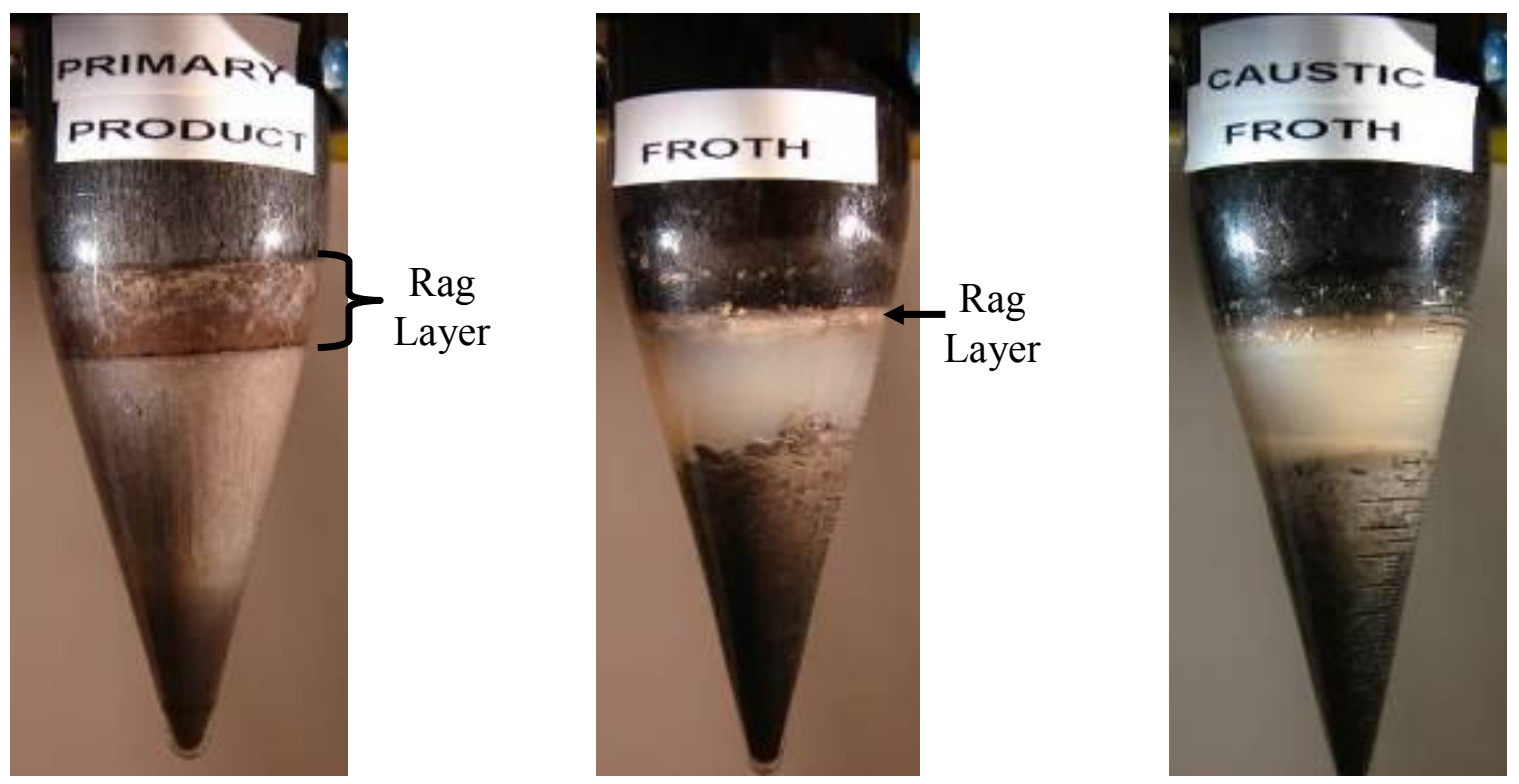

FIG. 1. Diluted bitumen emulsion test of the primary recovery product, untreated froth and caustic treated froth showing the formation of a rag layer emulsion during a froth treatment simulation. The bitumen concentrate recovered from MFT produces a large stable emulsion layer. Further treatment with and without caustic shows almost no emulsion or rag layer when caustic is used to treat the MFT bitumen concentrate. When the rag layer was compared between the treated (caustic froth) and untreated (froth) no rag layer was isolated from the caustic froth but a substantial layer was isolated in the untreated froth.

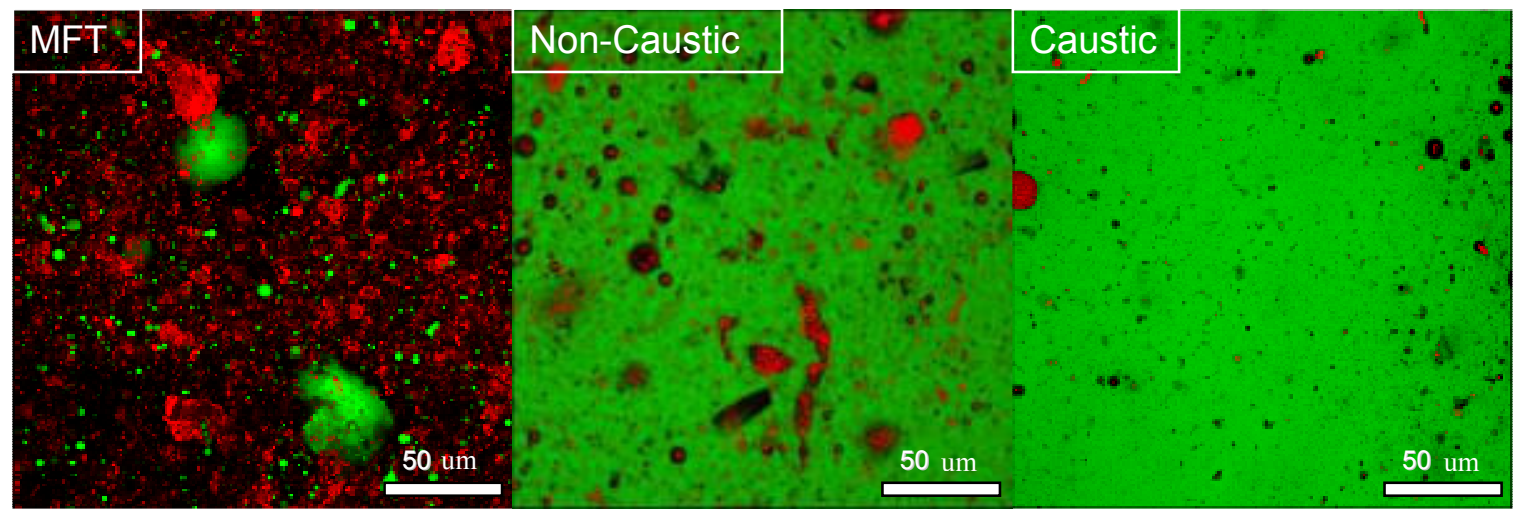

FIG. 2. Comparison between the bitumen froths obtained from the two-step extraction process from the mature fine tails (MFT) with $\mathrm{NaOH}$ treatment (caustic) and no chemical treatment (non-caustic). The red is the mineral phase and the green is the hydrocarbon or bitumen. Strong associations between the bitumen and mineral are seen in the original MFT sample, and in the non-caustic or untreated froth. The treatment of the primary recovery product with $\mathrm{NaOH}$ (caustic) removes most of the solids and evidence of surfactants in the bitumen, producing a high quality froth. This high quality froth then produces very little emulsion or rag layer in the subsequent processing steps. 